\title{
MAX WEBER O EL ENIGMA EMOCIONAL DEL ORIGEN DEL CAPITALISMO
}

\author{
Eduardo Bericat Alastuey
}

Universidad de Málaga

\section{RESUMEN}

Un minucioso análisis metateórico de las teorías sociológicas elaboradas por los sociólogos clásicos revela el hecho, sorprendente para la mentalidad "moderna" de los sociólogos que les han sucedido, de que la estructura teórica de cualquier teoría sociológica resulta a la postre ininteligible si no se consideran las emociones implicadas en los fenómenos sociales que tales teorías tratan de explicar o comprender.

La afirmación precedente puede constatarse en La ética protestante y el espiritu del capitalismo, de Weber, una de cuyas claves explicativas resulta ser la humillación que la doctrina protestante proyecta sobre sus fieles. Weber sostuvo que el dogma de la predestinación, esto es, la imposibilidad humana de conocer los designios divinos, está en la base de la emergencia del ethos capitalista. Incapaces de saber si alcanzarían la salvación extramundana, angustiados por esta absoluta falta de certeza, los calvinistas encontraron en el éxito intramundano tanto una especie de señal sobre los designios divinos como un remedio para calmar su profunda angustia. Lo importante para Weber, sin embargo, no eran los contenidos cognitivos del dogma de la predestinación, sino el estado vivencial en el que éstos ponían al creyente. Una idea es incapaz de tener efectos en la conducta si no es mediante la modificación de algunos estados emocionales del sujeto.

La angustia, sin embargo, es un sentimiento demasiado genérico e indefinido como para conocer sus efectos conductuales. Un detenido análisis del enorme contenido emocional presente en la obra de Weber revela que la angustia a la que siempre se refiere es la angustia provocada por la humillación del hombre. El Dios que dibuja la doctrina protestante proyecta sobre el hombre una triple humillación: nada puede saber sobre su designio futuro (humillación cognitiva); no merece ningún respeto ante Dios (humillación valorativa); y no tiene ningún derecho a la felicidad (humillación emotiva). No es extraño, por tanto, que el ser humano buscase un nuevo Dios en el que recuperar su orgullo. Éste fue, precisamente, el ardid de la razón sobre el que se 
sustentó el radical cambio de valores que dio lugar a la emergencia del capitalismo. Seres humanos que adoraban por encima de todas las cosas a Dios, acabaron adorando al Becerro de Oro.

\section{INTRODUCCIÓN}

La tesis expuesta por Weber en su obra La ética protestante y el espiritu del capitalismo es quizá la teoría más conocida de toda la historia de la sociología. No pretendemos, por este motivo, exponer de nuevo una versión canónica ajustada al modelo típico de las recensiones metateóricas al uso en cualquier texto de sociología. Nuestra intención no es otra que llevar a cabo una relectura de este texto clásico que, manteniéndose fiel a su contenido, ponga de relieve un importante aspecto casi siempre olvidado. En concreto, nos referimos al papel que juegan las emociones en la teoría weberiana del origen del capitalismo.

Creemos que incluso el mismo Weber no fue consciente de la riqueza de los contenidos emocionales que él mismo introdujo en el núcleo de su tesis. En el texto hay muchas más referencias a los sentimientos que las incluidas en la explícita síntesis final de su modelo teórico. Éste es uno de los motivos que explica el hecho de que la mayoría de las recensiones conocidas incurran en idéntico error. Weber redujo el eslabón emocional de su tesis a la angustia cognitiva producida en los fieles por el dogma de la predestinación. No sólo la incertidumbre, sino la absoluta imposibilidad de saberse elegido, llevó al puritano a encontrar en el éxito terrenal un indicio del estado de gracia que operaba en él. Sin embargo, como veremos seguidamente, la emoción clave del modelo, la única que podía resolver la paradoja histórica de querer por encima de todas las cosas adorar a Dios y, sin embargo, acabar adorando al becerro de oro, no es una angustia genérica, sino la angustia que produjo una cruel humillación derivada del sistema dogmático impuesto por la reforma protestante, en especial por su versión puritana y calvinista.

Con esta nueva interpretación no creemos que se pervierta el sentido original y genuino de la tesis weberiana. Antes al contrario, tan sólo pretendemos poner de manifiesto un elemento fundamental al que el autor dedicó innumerables páginas y matizados argumentos. El hecho de que este complejo y rico conglomerado de argumentos emocionales no quedara reflejado en la síntesis final puede deberse, en nuestra opinión, a dos causas. La primera estaría relacionada con la nación alemana, afectada desde hace varios siglos por diversas humillaciones históricas (Berlin, 1999). A buen seguro, un pensador alemán como Weber era el menos indicado para tratar explícitamente con los sentimientos de humillación (Scheff, 1994). La segunda no estaría asociada a esta emoción en particular, sino a las emociones en general. Como fundador de la sociología, en una época en que el positivismo hegemonizaba todo modelo de ciencia, Weber tendió más bien a ocultar las emociones contenidas en su tesis, como así lo hizo, incluso con mayor empeño, toda la sociología posterior (Scheff, 1990a). 


\section{EL ENIGMA DEL ORIGEN DEL CAPITALISMO}

La teoría de Weber pretendió aportar luz a un enigma que ha cautivado, y todavía cautiva, a gran parte de los científicos sociales. El enigma se funda en la imposibilidad de explicar por qué ciertas sociedades, en un determinado momento de su historia, establecen un modo de existencia basado en un evidente absurdo. En el origen del capitalismo, encontramos a un ser humano en frenética actividad que renuncia a los frutos de su trabajo. Tanto el empresario como el trabajador están sometidos a este doble sacrificio, típico del proceso de industrialización de la era moderna. El sudor del trabajo no viene acompañado por el disfrute de un mayor bienestar, sino por el sabor amargo de una severa renuncia. Las consecuencias de la actividad laboral no revierten en beneficio de los sujetos que la llevan a cabo. Reina una radical ruptura de la cadena natural de la motivación humana, cadena que liga al hombre con el mundo por medio de las consecuencias de su actividad. "Acción» y «renuncia», diría Weber, se condicionan recíprocamente de modo inexorable en el mundo de hoy (Weber: 199) ${ }^{1}$.

Para entender el verdadero valor e interés de la tesis de Weber es preciso ser consciente de las dificultades que nos encontraremos al pretender hacer inteligible este peculiar comportamiento. De una parte, es difícil explicar que un ser humano preocupado ante todo por la salvación en el otro mundo mostrara un afán tan persistente por el trabajo terrenal. De otra parte, es difícil explicar que un ser humano motivado por intereses puramente terrenales renunciara con tanto rigor al bienestar que su trabajo hubiera podido proporcionarle. Si la actividad del hombre ha de justificarse por los valores que rigen la conducta, nos encontramos ante un evidente contrasentido. ¿Cómo explicar que hombres de profundas creencias religiosas tuvieran tal éxito en la acumulación de riqueza? Cuando la salvación constituye el fin primordial de la vida, y la rectitud moral el único modo de llegar a él, extraña sobremanera encontrar a los seres humanos trabajando sin descanso de sol a sol. Pero si pretendemos entender la conducta en virtud de los intereses o necesidades que satisface, siguiendo la teoría utilitarista de la acción social, el hombre dedicado a acumular riqueza nos sorprende desde el momento en que renuncia a ella. ¿Cómo se explica que hombres con arraigados afanes materialistas pudieran repudiar los dulces placeres que puede proporcionar la riqueza? Desatados los deseos cuando su satisfacción está al alcance de la mano, nada hubiera podido refrenarlos hasta el punto de trasmutar las motivaciones que alentaban el duro trabajo en la rigurosa frugalidad de su peculiar modo de existencia. Mírese por donde se

1 Todas las referencias al texto de Weber se refieren a la siguiente edición: M. Weber (1998), Ensayos sobre sociología de la religión, I, Madrid, Taurus. De ahí que en las referencias a este texto sólo se incluya el número de página. Esta reciente versión ha corrido a cargo de José Almaraz y Julio Carabaña. Consideramos que esta versión mejora sensiblemente la primera traducción realizada al español por Luis Legaz Lacambra, y publicada por Ediciones Península en 1969. 
mire, nos enfrentamos a un evidente dilema. El doble y simultáneo sacrificio necesario en el origen del proceso de industrialización, que consistió en trabajar mucho $y$ consumir poco, es a todas luces ininteligible. Y, sin embargo, fue este doble sacrificio el que sentó las bases sociales de la acumulación originaria de capital que más tarde daría lugar al capitalismo (Tawney, 1959).

Muchos pensadores, entre los que se encontraba Simmel, trataron de explicar el fenómeno recurriendo a una patología del deseo: la avaricia (Simmel, 1977). El mero afán de acumular riqueza es un deseo absurdo por cuanto no llega a realizarse en un disfrute real. La riqueza objetualizada en dinero desaparece en cuanto pretendemos satisfacer con ella necesidades concretas. El avaro, por muy grande que sea su riqueza, obtiene una sola satisfacción. En el resto, es tan pobre como los más pobres. El dinero es por tanto riqueza potencial, y sólo permanece, y eventualmente aumenta, a condición de que no lo cambiemos por otros objetos de deseo. También Marx alude a la «sed abstracta de placeres» del capitalista, frente a la satisfacción de necesidades concretas, pero al menos concibe esta sed como una constricción del sistema, no como una patología individual (Marx, 1972). De hecho, la explicación por la avaricia no es una explicación, sino en todo caso un nombre o etiqueta que se le adjunta a esta extraña conducta. Weber rechaza este tipo de interpretaciones. La avaricia no puede explicar el afán de lucro propio del capitalismo. En primer lugar, porque afán de lucro ha existido en todo los sistemas socioeconómicos. Una guerra de saqueo o la piratería también podrían justificarse de este modo. Para Weber, el capitalismo implica, más bien, una contención del afán de lucro, una avaricia racionalizada cuya meta es la obtención de una ganancia constante. El impulso adquisitivo se encuentra en todos los tipos de personas y en todas las épocas, allá donde existan posibilidades objetivas de enriquecimiento. Pero la codicia ilimitada nada tiene que ver con el capitalismo, «más bien al contrario, debería considerarse al capitalismo como el freno o, por lo menos, como la moderación racional de este impulso irracional» (Weber: 14). Identificar un impulso tan universal, como la avaricia, a una estructura socioeconómica tan particular, como el capitalismo, constituye una simpleza histórica.

Marx y Weber ofrecen explicaciones complementarias, aunque el primero piensa en términos de capitalismo ya instituido. Marx explica este doble sacrifico en clave de poder. El sistema capitalista se impone a los empresarios, obligados a acumular capital si quieren garantizar la supervivencia de su empresa. Los empresarios se imponen a los trabajadores, obligados por su carencia de medios de producción a renunciar al producto de su actividad (Marx, 1964). La teoría de Marx se centra en el doble sacrificio del trabajador en tanto alienación (Giddens, 1977). Weber explica este doble sacrifico en clave de conciencia. Tanto empresarios como trabajadores trabajan mucho y consumen poco debido a las implicaciones prácticas de unas creencias religiosas que disciplinan por igual a ambos. "El empresario burgués podía y debía guiarse por su interés de lucro, con conciencia de estar en plena gracia de Dios [...]. Además, el gran poder del ascetismo religioso ponía a su disposición trabajadores sobrios, hon- 
rados, de gran resistencia y lealtad para el trabajo, considerado por ellos como un fin de vida querido por Dios» (Weber: 195). Si bien la teoría de Weber se centra fundamentalmente en el empresario en tanto acumulador, la clave metodológica estriba en que es originalmente una cultura, no un sistema económico ya establecido, la que se le impone.

En ambas explicaciones, marxista y weberiana, los dogmas utilitaristas son puestos radicalmente en cuestión. Para Marx, es el poder el que determina el evidente absurdo de la alienación en el capitalismo. Sólo la coacción podría explicar la miseria del proletariado en medio de una cada vez mayor abundancia (Marx, 1972). Para Weber, sólo la irracionalidad, la fuerza vital de unas creencias religiosas, podían dar origen y sentido a ese modo de existencia (Weber, 1998). El individuo, desde su perspectiva, no actúa libre y racionalmente con arreglo a sus intereses. No es libre al principio, pues está sometido al imperativo de la salvación derivado de su religiosidad. $\mathrm{Ni}$ lo es al final del proceso, una vez que el sistema se instala como orden socionatural y restringe la libertad de los hombres en una ya finalmente secularizada jaula de hierro. «El puritano quería ser un hombre profesional; nosotros tenemos que serlo. Pues al trasladarse la ascesis desde las celdas monacales a la vida profesional y comenzar su dominio sobre la moral intramundana, contribuyó a la construcción de este poderoso cosmos del orden económico moderno que, amarrado a las condiciones técnicas y económicas de la producción mecánico-maquinista, determina hoy con fuerza irresistible el estilo de vida de todos cuantos nacen dentro de sus engranajes» (Weber: 199). Es la interpretación histórica del origen del capitalismo, y el papel de las ideas en este proceso de cambio social, lo que separa a Weber y a Marx.

Ambas teorías comparten, también, su objeto de estudio. La realidad de un capitalismo naciente en proceso de acumulación en el que apenas se podía entrever lo que hoy ya resulta obvio, un capitalismo de consumo frente al originario capitalismo de producción. Esto no significa que en el capitalismo de consumo no se mantenga el ethos productivista que describió Weber, ni la coacción alienante de la que habló Marx. Significa, eso sí, que el doble sacrificio se ha atenuado si lo comparamos con el exigido en la época del denominado capitalismo salvaje, que fundamentó la acumulación originaria de capital (Marx, 1964). Se han dulcificado las condiciones de trabajo, el esfuerzo laboral de producción, y se ha dulcificado la absoluta renuncia de consumo que marcó al hombre en las primeras etapas de la industrialización. La teoría marxista de las clases sociales expresa la dinámica del conflicto que exigió progresivamente la renuncia de la renuncia. Dinámica fundamentada en la frustración proletaria de la espera. La teoría de Weber, por su parte, se mantiene viva en cuanto sacralización de la actividad mundana. La teoría utilitarista, finalmente, se impone en tanto equilibrio entre el moderado trabajo y la moderada renuncia, en tanto disolución del ascetismo intramundano en puro utilitarismo, tal y como pronosticó Weber (Weber: 201).

En suma, la acumulación capitalista se basaba en el desarrollo de una 
intensa actividad cuyas consecuencias, lejos de satisfacer las necesidades inmediatas de los hombres, se transformaban en dinero. Este dinero servía para invertir en medios de producción que, de nuevo, no servían para satisfacer necesidades concretas, sino para invertir en más medios de producción. Circuito helicoidal, alimentado por la sacrificada actividad del hombre, cuyas consecuencias positivas de consumo no repercutían en el mismo hombre. Ese hombre de carne y hueso que soportó sobre sus espaldas un trabajo del que nunca jamás extrajo beneficio alguno, que nunca jamás pudo disfrutar. Explicar este doble sacrifico queda bastante lejos de cualquier aproximación utilitarista de la estructura y de la acción social.

\section{APROXIMACIÓN TEÓRICO-METODOLÓGICA}

El problema explicativo-comprensivo que acometió Weber no estriba tan sólo, como señala Aron, en demostrar que la «orientación del interés de cada uno está regida por su visión del mundo" (Aron, 1980: 275). De haber sido éste el problema, la tesis hubiera carecido de originalidad. Lo que Weber quería hacer inteligible era la paradoja inscrita en el hecho de que hombres que adoraban por encima de todo a Dios, acabaran adorando por encima de todo al Becerro de Oro. Es decir, le preocupaba cómo se había producido un profundo y paradójico cambio social, aquel que condujo al hombre desde unos valores supremos hasta otros diametralmente opuestos. En suma, el cambio desde un dios-Dios a un dios-dinero.

El punto de arranque de Weber fueron las correlaciones estadísticas detectadas entre adscripción a una determinada confesión religiosa, por un lado, y la propiedad de capital y la ocupación de puestos directivos de empresa, por otro: "Cuando se pasa revista a las estadísticas profesionales de aquellos países en los que existen diversas confesiones religiosas, suele ponerse de relieve un fenómeno [...]: es el carácter eminentemente protestante tanto de la propiedad y empresas capitalistas, como de las capas especializadas de trabajadores, y sobre todo del alto personal de las modernas empresas, de superior preparación técnica y comercial» (Weber: 26). Inicialmente, Weber destaca el hecho de que, en el siglo XVI, aquellos territorios más desarrollados se hubieran adscrito y hubieran apoyado más incondicionalmente la Reforma, lo que no dejaba de parecerle una paradoja. Teniendo en cuenta que el calvinismo constituía la forma más insoportable de control sobre la vida individual, sustituyendo el dominio eclesial sobre la vida por un dominio interno mucho más fuerte, Weber se pregunta por qué fueron "precisamente esos países económicamente desarrollados, y dentro de ellos, como todavía veremos, las clases medias "burguesas" entonces nacientes, los que no sólo aceptaron esta tiranía puritana hasta entonces desconocida, sino que incluso pusieron en su defensa un heroísmo del que la burguesía raramente había dado prueba hasta entonces" (Weber: 28). Estos datos parecían mostrar una afinidad electiva entre una cons- 
telación religiosa y el modo de vida capitalista y burgués que conducía al desarrollo económico.

Pero Weber no se detuvo en la mera constatación de estas correlaciones, reveladas por unos análisis cuantitativos suficientemente conocidos en su época. Quería mostrar el modelo de conexiones comprensivas que dieran sentido a la relación detectada entre ambas variables. Por este motivo hubo de acometer análisis cualitativos que hicieran inteligible tal relación. La metodología cualitativa sigue al descubrimiento verificado por la metodología cuantitativa (Bericat, 1998). Una constelación simbólica, una religión, está asociada a unas específicas conductas. Dado que estas conductas contradicen en apariencia el sentido de esa constelación, es preciso elaborar un modelo más complejo que dé cuenta de sus vínculos. Es decir, hay pruebas de que la ética protestante está correlacionada con el espíritu del capitalismo, pero es preciso construir el sentido de la conexión descubierta, elaborar un modelo que clarifique la pauta verificada cuantitativamente.

Este modelo que vincula conciencia y conducta constituye la aportación fundamental de Weber. Una atenta consideración de las conexiones que establece en su tesis revela y confirma la triple composición de la conciencia. Desde nuestro punto de vista, la dimensión intercomunicativa o simbólica del ser humano siempre trabaja con tres componentes fundamentales: a) cognitivos; b) valorativos, y c) emotivos (Bericat, 1999). En la tesis weberiana, el componente valorativo está asociado a la salvación como el bien más querido. Si los valores son criterios de deseabilidad ordenados jerárquicamente, no existía para aquellos hombres otro valor más deseado que lograr la salvación eterna. El componente cognitivo se refiere a la dogmática o sistema de ideas que acompañan a las determinaciones de valor. El dogma que se incluye en el modelo no es otro que la idea de predestinación, la creencia de que cada individuo está predestinado desde la eternidad a la salvación o a la condenación de su alma. Por último, el componente emotivo que entra en el modelo es la angustia producida por el cruce entre el valor más estimado (la salvación) y la imposibilidad de saber si será logrado (la predestinación). Angustia en la perpetua incertidumbre de la vida. Como vemos, sólo la presencia conjunta de este específico valor, de este concreto sistema de ideas y de esta particular emoción, puede justificar y explicar las conexiones entre religión protestante y espíritu del capitalismo.

Es importante resaltar la escasa importancia que se ha otorgado al componente emocional en la tesis weberiana, pese a sus esfuerzos por mostrar que la clave de las conexiones existentes entre adscripción religiosa y conducta práctica se encuentra precisamente en los estados afectivos a los que es abocado el sujeto. Weber refiere en muchas ocasiones este componente. Sin embargo, como sucede a otros muchos autores clásicos, estas referencias están más o menos encubiertas bajo diversas denominaciones. Es claro que para él los elementos cognitivos y valorativos del complejo simbólico que constituye una religión no pueden tener, por sí mimos, un impacto eficiente en la conducta humana. Esto lo señala muchas veces en sus escritos sobre religión: «Espero que en el curso 
de la propia exposición resulte cada vez más claro lo que debe entenderse por "ética económica" de una religión. Lo que importa no es la teoría ética de los compendios teológicos, que sólo sirve como un medio para su conocimiento (muy importante en ciertas circunstancias), sino los estímulos prácticos para la acción fundamentados en las implicaciones psicológicas y pragmáticas de las religiones» (Weber: 234). En este mismo sentido, Weber advierte: "Es preciso separar cuidadosamente, como repetidamente tendremos ocasión de ver, aquello a lo que una orientación religiosa determinada aspiraba como ideal de lo que ejercía influencia práctica sobre sus adeptos»(Weber: 36). E insiste: «no nos interesa a nosotros, por ejemplo, lo que de un modo teórico y oficial se enseñaba en los compendios morales de la época [...], sino algo totalmente muy distinto: indagar cuáles fueron los impulsos psicológicos creados por la fe religiosa y la práctica de la religiosidad, que marcaron la orientación del modo de vida y mantuvieron dentro de ella al individuo» (Weber: 91).

Pero aunque Weber señaló con toda firmeza, tal y como hemos visto, la incapacidad de los elementos dogmáticos o teóricos (cognitivos) para afectar directamente la conducta, no dejó de señalar, con idéntica firmeza, que «estos impulsos nacían en gran parte de la peculiaridad de las creencias religiosas» (Weber: 91). Por este motivo, Weber advierte que «el contenido conceptual de una religión tiene un alcance más amplio del que le concede, por ejemplo, William James». La vivencia religiosa es irracional, pero eso «no impide que, prácticamente, sea de suma importancia la clase de sistema intelectual que confisca, por así decirlo, para sí la vivencia religiosa inmediata, marcándole la ruta a seguir» (Weber: 115). Weber no considera a las emociones, como parecía defender James, como unas realidades últimas e inexplicables, sino que establece adecuadas conexiones entre ellas y los otros dos componentes de la conciencia.

En suma, en el modelo teórico de Weber lo importante es la vivencia, así como los impulsos que naciendo de esta vivencia determinan el comportamiento de los sujetos. Pero esta vivencia no es un elemento simple del existir. En ella se integran de un modo peculiar un sistema de valores, un sistema conceptual y un sistema emocional. Su posición al respecto no es unilateral, como la de otros pensadores. Rechaza un análisis lógico de la religión, así como un análisis basado exclusivamente en las creencias, insistiendo en la importancia de los impulsos prácticos que las ideas pueden generar en los individuos. También rechaza un análisis puramente emocional de la vivencia religiosa, señalando acertadamente que los sistemas de ideas condicionan las emociones pertenecientes a una vivencia particular. Su modelo se construye, por tanto, sobre la interdependencia de los tres componentes citados, los cognitivos, los valorativos y los emotivos.

Hemos de señalar ahora cómo Weber encubre hasta cierto punto el componente emocional, tan clave en su modelo, recurriendo bien a otros términos genéricos, bien al calificativo de psicológico. Así, cuando habla de los estímulos prácticos para la acción fundamentados en las implicaciones psicológicas y pragmáticas de las religiones, la referencia emocional es clara. Una idea sólo 
puede tener efecto sobre la conducta en la medida que active el organismo, activación que sólo puede producirse por la presencia de una determinada carga emocional. Lo curioso es que el calificativo de "psicológico" se emplee siempre en Weber para referir estados emocionales, como si los estados afectivos, en tanto objeto de estudio, fueran patrimonio de la psicología. Es cierto que las emociones pertenecen al orden más íntimo de la subjetividad, pero no es menos cierto que también las «ideas» y los «valores» pertenecen a ese mismo orden. ¿Por qué, entonces, la renuncia sociológica a contemplar las emociones si, como vemos, forma parte esencial del modelo? Mientras existe una sociología del conocimiento, y se está desarrollando un sociología de los valores, apenas se ha desarrollado, pese a este ejemplo clásico de utilización, una sociología de las emociones. En el modo de existencia de una colectividad, el saber, el valer y el sentir se recrean tanto en los procesos colectivos de intercomunicación como en los procesos individuales de la conciencia. En este sentido, no existe ninguna diferencia entre estos tres componentes. A menos que las emociones se consideren en un sentido puramente orgánico (Hochschild, 1983), es decir, como impulsos instintivos inexplicados e inexplicables socialmente, esta actitud no tendría sentido (Bericat, 2000). Pero Weber nos muestra, como veremos, la producción social de la emociones en un contexto histórico determinado.

En suma, Weber descubre una correlación cuantitativa entre un complejo simbólico-religioso y un determinado modo de vida caracterizado por unas conductas prácticas. Al intentar hacer inteligible esta relación, se ve abocado a señalar que lo importante no son los dogmas ni las creencias, sino el estado emocional en que éstos ponen al individuo. De este modo pone en claro la ineficacia de la ideas para influir directamente en la conducta, pero también pone en claro que las emociones dependen del complejo de ideas (Hume, 1981). Así, un valor supremo, la búsqueda de la salvación en el otro mundo, condicionado por un sistema de ideas, el dogma de la predestinación, crea en los sujetos unos estados afectivos que impulsan la conducta práctica en una determinada dirección. Éste es el circuito complejo mediante el que hay que explicar el enigma del origen del capitalismo, el doble sacrificio de la actividad y la renuncia, así como la paradoja de convertir el amor simbólico a Dios en un amor práctico al Dinero. Modelo que constituye una advertencia clara contra una sociología del conocimiento y de los valores que quieren extraer conclusiones simples sobre posibles efectos directos. La vivencia subjetiva es lo que importa y, dentro de esta vivencia, se cuece una amalgama de valores, creencias y emociones que es preciso investigar en conjunto, no aisladamente, para poder explicar los efectos prácticos sobre la conducta. La emoción no puede quedar fuera, pues forma parte del magma de la conciencia, la parte, por así decirlo, más pegada al cuerpo. La emoción es la conciencia del cuerpo.

En palabras de Parsons, "no es el mero mandato verbal de ciertos tipos de conducta, emitido por representantes o líderes de cuerpos religiosos, al que se adhieren estas masas de hombres, del que depende el razonamiento de Weber». 
«El interés de Weber no se limita, en modo alguno, a las consecuencias lógicas del sistema inicial de ideas religiosas, o a los deseos directamente expresados por los líderes religiosos de una conducta práctica basada en ellas. Se ocupa, más bien, de las consecuencias totales del sistema religioso. Esto implica dos puntos importantes: en primer lugar, las consecuencias importantes son, como dice, psicológicas, más que puramente lógicas. Las consecuencias lógicas actúan, pero no solas. Deben ser tomadas junto con la constelación de intereses implicados, que puede, como entre dos alternativas lógicas igualmente posibles, influir sobre la acción en la dirección de una, o incluso inhibir el desarrollo de las plenas consecuencias lógicas en algunas otras direcciones» (Parsons, 1968: 645). Sólo una consideración plena de la vivencia, a la luz de todos los elementos básicos de la conciencia, puede hacer inteligible la conducta humana.

\section{EL DOGMA DE LA PREDESTINACIÓN}

Ya hemos señalado que la orientación teórico-metodológica de Weber implicaba un juego de elementos culturales o intersubjetivos en el que los valores precedentes se combinaban con una determinada doctrina para dar lugar a una vivencia con un estado emocional que generaba impulsos de acción orientados intramundana y racionalmente. Nos interesa ahora destacar cuáles fueron, a juicio de Weber, estos impulsos, para ofrecer más adelante una versión más definida y minuciosa de la participación emocional en los cambios hacia el espíritu empresarial y burgués. Como es sabido, Weber se detuvo a considerar los efectos vivenciales del dogma de la predestinación. Según este dogma, ninguna persona podía saber si él estaba entre los designados por Dios para la salvación eterna. Estos designios arbitrarios e inescrutables dejaban al fiel en una situación de completa angustia e incertidumbre acerca de su destino extramundano. Esta incertidumbre, en el marco del valor supremo que constituía para ellos la salvación, les resultaba completamente insoportable. Así que el hombre, atizado por la angustia de saberse o no elegido, encontró en el ascetismo intramundano, en el éxito terrenal, la señal que necesitaba. Bien es cierto que las buenas obras no tenían ningún valor en sí, pues el hombre no era un ser ni responsable ni libre. Sin embargo, aquel hombre que mostrara una rectitud constante e inquebrantable en su conducta podía imaginar que obraba en él la gracia divina, cuya expresión era, precisamente, su comportamiento. Cuanto mayor fuera su rectitud y rigor moral, cuanta más constancia demostrase, en mayor medida podía suponer que estaba obrando en él la gracia divina. En esta misma medida, podría pensar, como Calvino, que él mismo era un instrumento de la divinidad.

Según lo dicho, los hombres no pueden conocer los designios divinos, tan sólo que unos se salvarán y que otros se condenarán. Nos encontramos ante un particularismo de la gracia ignoto. Nada puede saber el hombre, por eso Weber dice: «Estimamos que el problema fundamental a resolver es el de cómo pudo 
ser soportada esta doctrina en una época en la que la otra vida no preocupaba infinitamente más, sino que era además mucho más cierta que todos los intereses de la vida terrena. Todo creyente tenía que plantearse necesariamente estas cuestiones: ¿He sido yo elegido? ¿Y cómo estaré seguro de ello? Tales cuestiones relegaban a segundo término toda preocupación terrena» (Weber: 107). De aquí se deducen dos tipos de consejos pastorales: a) «se prescribe como un deber el considerarse elegido y rechazar como tentación del demonio toda duda acerca de ello, puesto que la poca seguridad de sí es consecuencia de una fe insuficiente $y$, por tanto, una acción insuficiente de la gracia», de ahí que se cultiven ahora "esos "santos" ciertos de sí mismos, que vemos personificados en ciertos hombres de negocios, puritanos y de acerada dureza de la era heroica del capitalismo», y b) "como medio principalísimo de conseguir dicha certeza en sí mismo, se inculcó el trabajo profesional incesante como único modo de ahuyentar la duda religiosa y de obtener la seguridad del propio estado de gracia» (Weber: 109). La ansiedad cognitiva de la incertidumbre se transmutaba en una conciencia cierta que rechazaba cualquier duda, y que exigía, en el plano práctico, una conducta regular y racional sin fisuras. Por otro lado, el trabajo incesante constituía un antídoto contra la duda que asalta la conciencia del hombre ocioso. Rectitud moral, renuncia material y éxito mundano constituían los tres reductores de la angustia.

Éste es, en esencia, el contenido emocional de la tesis expuesta explícitamente por Weber en su obra, y éste es el contenido que aparece recurrentemente en todas las interpretaciones realizadas por la sociología posterior. Es cierto que Weber considera explícitamente la incertidumbre, la ansiedad que produce, así como la consecuente búsqueda de la certitudo salutis, como el vínculo emocional clave que explica la proyección de la duda sobre el éxito intramundano. Ahora bien, esta interpretación literal de la obra de Weber, en lo que se refiere a las emociones, resulta demasiado pobre a la luz del texto integro de su propia obra. La sociología posterior nunca estuvo muy interesada por el elemento emocional de la conciencia y de la cultura, así que en este punto tomó literalmente, al pie de la letra, la síntesis realizada por el propio Weber. Como ya hemos dicho, en las páginas de la ética protestante y el espíritu del capitalismo se ofrece un tratamiento emocional mucho más rico y complejo, tratamiento que va mucho más allá de la mera ansiedad cognitiva (saber o no saber) señalada por el autor. En esta interpretación truncada del juego emocional en el que quedó inmerso el individuo, el conocimiento del estado de gracia constituía el hecho interpretativo esencial.

El escaso interés explícito que mantuvo Weber por la conexión emocional de su modelo se muestra en el modo en que alude a la principal emoción que forma parte del mismo: la angustia. Utiliza el concepto de angustia como un concepto genérico que no alude a ninguna emoción definida conceptualmente en el marco de una teoría científica. Su significado no parece más preciso que el que pudiera otorgarle el sentido común o el uso cotidiano de la palabra. Además, su asociación con el mero hecho de conocer o no el estado de gracia 
vincula la angustia a aspectos cognitivos de la conciencia, tal y como era de esperar en una época donde la razón parecía enseñorearse con el mundo. Ahora bien, este escaso interés explícito de Weber contrasta con la implícita riqueza emocional de su tesis. Contraste y ambigüedad que no ha de extrañarnos cuando se trata de la obra de sociólogos clásicos. Por un lado, influidos por la tradición pre-racionalista, eran incapaces de pensar el mundo y la acción social sin considerar el mundo de las emociones. Por otro, empeñados en la tarea de fundamentar una "ciencia» social que mereciera tal nombre, simulaban o reprimían toda referencia emocional. Cuando esto no era posible, como sucede en la tesis weberiana, podían adoptarse algunas otras soluciones aceptables. Asociar la emoción lo más íntimamente a un hecho racional o de conocimiento. Utilizar términos sustitutivos que redujeran la frecuencia de las referencias emocionales explícitas. $\mathrm{O}$ mantener la indefinición de los conceptos emocionales, para así reducir su estatuto categorial en la teoría.

Realizando una lectura minuciosa del propio texto de Weber, interpretando lo que se nombra y también lo que se sugiere, restituyendo el valor categorial de las emociones en su modelo, y tratando de definir conceptualmente, en el marco de una teoría, la emoción que finalmente da sentido y completa las conexiones básicas de la tesis, sostenemos que el estado afectivo en que el calvinismo deja al ser humano es el de una completa humillación, sentimiento que pertenece a la familia emocional de la vergüenza, y que encuentra en la ética protestante la más depurada expresión que pueda registrarse en la historia de las religiones. Una completa y cruel humillación proyectada sobre los seres humanos, como la que representó el calvinismo en los inicios de la modernidad, no podía dar como resultado sino el distanciamiento entre el ser humano y su Dios. Éste es el punto esencial del ardid de la razón, que diría Hegel, y que explica el origen del capitalismo y el gran cambio social que supuso la sustitución del dios-Dios por el dios-dinero.

\section{LA HUMILLACIÓN DEL CALVINISMO}

Si la muerte equivale a la aniquilación física en la dimensión interactiva de la sociabilidad, la humillación significa la aniquilación simbólica en la dimensión intercomunicativa de la sociabilidad. La humillación es un sentimiento que forma parte de la familia emocional de la vergüenza, y bien pudiéramos verla como su manifestación más extrema y absoluta. La vergüenza, según expuso con genial sencillez Ch. H. Cooley al fundamentar su teoría del "yo espejo", es la emoción que sentimos al imaginar la percepción negativa que los otros significativos tienen de nuestra persona (Cooley, 1902). Orgullo y vergüenza señalan posiciones en las escalas de valor proyectadas sobre nosotros por los demás (Smith, 1997). Pero si la vergüenza es, de por sí, un sentimiento muy doloroso (Lewis, 1971), la humillación expresa la insoportabilidad de la aniquilación del ser social que todos llevamos dentro. En la humillación mori- 
mos a los ojos de los demás, alcanzando el cero absoluto de la dignidad. Es la carencia absoluta del valor simbólico creado intersubjetivamente.

Pongámonos ahora, como aconseja Weber, en la piel de un ser que vive en el seno de una cultura profundamente religiosa, para quien Dios constituye el otro significativo por excelencia. En este seno, como ya hemos dicho, su máxima pretensión y preocupación era la salvación del alma. Para él no existe otro objetivo o interés ni más querido ni más sublime, y hacia allí debe orientar todos sus desvelos y esfuerzos, precisamente allí donde reside todo valor. Y ahora escuchemos algunos párrafos de la Westminster confesión, del año 1647, desde la perspectiva de ese hombre preocupado esencialmente por la salvación:

«Capítulo 9. (Del libre albedrío). Número 3: Al caer el hombre en el pecado, su voluntad ha perdido completamente la capacidad de encaminarse al bien espiritual y a la bienaventuranza, de modo que el hombre natural, apartado por completo del bien y muerto en el pecado, no es capaz de convertirse ni aun de prepararse para ello.

Capítulo 3. (Del eterno decreto de Dios). Número 3: Para revelar su majestad, Dios por su decreto [...] ha destinado (predestinated) a unos hombres a la vida eterna y sentenciado (foreordained) a otros a la muerte eterna. Número 5: Aquellos hombres que están destinados a la vida han sido elegidos en Cristo para la gloria eterna por Dios, antes de la creación, por su designio eterno e inmutable, su decreto secreto y el arbitrio de su voluntad, y ello por libre amor y gracia; no porque la previsión de la fe o de las buenas obras o de la perseverancia en una de las dos $u$ otra circunstancia semejante de las criaturas le hubiesen movido a ello, como condición o como causa, sino que todo es premio de su gracia soberana. Número 7: Plugo a dios olvidarse de los restantes mortales, siguiendo el inescrutable designio de su voluntad, por el que distribuye o se reserva la gracia como le place, para honra de su ilimitado poder sobre sus criaturas, ordenándolos a deshonor y cólera por sus pecados, en alabanza de su justicia.

Capítulo 10. (Del llamamiento eficaz). Número 1: Place a Dios llamar eficazmente por su palabra y su espíritu a todos aquellos a quienes ha destinado a la vida, y sólo a éstos, en el tiempo conveniente y señalado por Él [...], quitándoles su corazón de piedra y dándoles un corazón de carne, renovando su voluntad y decidiéndolos, por su fuerza omnipotente, a optar por lo que es bueno [...]

Capítulo 5. (De la providencia). Número 6: Por lo que respecta a los hombre malos e impíos, a los que Dios, como juez justo, ha ofuscado y endurecido por pecados anteriores, no sólo los priva de su gracia, por la que su inteligencia podría haberse iluminado y su corazón haber sido tocado, sino que a veces les retira también los dones que tenían y los pone en relación con objetos de los que su corrupción hace una ocasión de pecado, entregándolos además a su propios placeres, a las tentaciones del mundo y al poder de Satanás, de donde sucede que se endurecen a sí 
mismos hasta por los mismos medios de que se sirve Dios para ablandar a otros» (Weber: 94-95)².

En estos párrafos encontramos en estado químicamente puro el mayor proyecto religioso conocido en la historia para provocar la humillación simbólica del ser humano. Weber citó estas líneas para mostrar el dogma de la predestinación calvinista, e interpretó exclusivamente su significado en clave cognitiva. Centró su atención sobre el hecho de conocimiento de que el hombre nada podía saber acerca de su destino, nada en absoluto. El «decreto secreto», el "inescrutable designio», muestran sin lugar a dudas la absoluta incapacidad de la inteligencia y de los poderes cognitivos del hombre para conocer su destino. Pero muestran, un poco más allá, el escaso valor de la inteligencia que, desprendida de la gracia, resulta inútil en tanto instrumento al servicio de Dios, en tanto lámpara que podría iluminar el sendero moral que nos conduciría hasta el Ser Supremo y su gloria. El inescrutable designio es motivo de una gran angustia provocada por la incognoscible incertidumbre que afecta a nuestro destino. Pero es motivo de una gran humillación, puesto que representa ante todo una radical incapacidad de la mente humana para descifrar o comprender la mente divina. Aquí encontramos la primera radical separación entre el hombre y Dios. El hombre que nada puede saber del Dios que todo lo sabe. Desaparece, así, la intercomunicación cognitiva entre lo humano y lo divino.

En toda religión, si pensamos ahora en el orden de los valores, corresponde al ser humano una actitud de humildad desde la que se expresa el respeto, a veces incluso reverencial, por los seres divinos. Los dioses configuran simbólicamente la esencia de los valores, el espacio celestial al que aspiran y en el que se reflejan, si bien a una escala menor y en una medida deficiente, todos los hombres de una comunidad. Esta ordenación jerárquica del valor anima los esfuerzos asociados a la renuncia que toda moral social impone en tanto sacrificio de la persona. Sin embargo, esta jerarquía no cierra la puerta a la recompensa moral que siempre en alguna medida dignifica al hombre. Los seres humanos y los dioses, de este modo, pueden en el orden de los valores entrar en comunicación, participar, si bien en diferente grado, de una misma sustancia moral. Éste, sin embargo, no es el caso ante el que nos encontramos. El hombre, en tanto hombre, ha caído en un absoluto pecado, es pecado. No en vano se le califica de "hombre natural» ${ }^{3}$, apartado completamente del bien y muerto en el pecado. No cabe mayor vergüenza ni humillación, pues el hombre es incapaz de convertirse al bien, ni aun de prepararse para ello. El ser humano no vale moralmente nada, y por si cupiese duda alguna, en los siguientes párrafos no ceja la insistente y desoladora desvalorización del hom-

2 Las cursivas son nuestras.

3 Hombre natural, en este sentido, se opondría a hombre moral. Esta radical oposición es, precisamente, la que inspira la filosofía moral de Kant, así como su creencia en la libertad humana. 
bre. Dios lo es todo, el ser humano nada vale. Dios predestina a la vida eterna a algunos hombres tan sólo "para revelar su majestad», "para la gloria eterna por Dios», "para honra de su ilimitado poder» y "en alabanza de su justicia». Difícil resulta concebir un Dios cargado de un desprecio tan profundo, pero la proyección humillante de la vergüenza no termina aquí. A la honra de su ilimitado poder se contrapone el mandato al «deshonor» de los hombres. Es el mismo Dios quien ordena su deshonra y su vergüenza. Es el mismo Dios quien los humilla, quien dictamina su absoluta pérdida de estatus moral.

Hemos visto que el hombre no sabe nada y no vale nada, pero además tampoco puede hacer nada para obtener la gracia. Se le define, sin paliativo alguno, como un ser carente de voluntad para encaminarse al bien espiritual. La impotencia de su voluntad es doble: simbólica y conductual. La fe, como creencia sentida en su Dios, de nada le serviría. Las buenas obras, tampoco. Todo es premio de su gracia soberana, sólo Él los decide, por su fuerza omnipotente, a optar por lo que es bueno. El contraste no puede ser mayor. Ellos nada pueden hacer, ni siquiera en la encrucijada sacra entre lo simbólico y lo conductual, esto es, en el orden del rito. Como señala Weber: «Este radical abandono (no llevado a sus últimas consecuencias en el luteranismo) de la posibilidad de una salvación eclesiástico-sacramental, era lo decisivo frente al catolicismo. Con él se consumó el desencantamiento del mundo que [...] rechazó como superstición y sacrilegio la busca de todo medio mágico para la salvación" (Weber: 98-99). Asimismo, nos dice que "también la confesión privada, contra la que el mismo Calvino sólo experimentaba algunos recelos por la posibilidad de alguna falsa interpretación sacramental, fue desapareciendo sigilosamente en las regiones donde el calvinismo se desarrolló con plenitud» (Weber: 101). En suma, ni poder simbólico, ni poder comportamental; tan sólo una absoluta impotencia humillantemente acrecentada por el deportivo «arbitrio de su voluntad» omnipotente. Ausencia de libertad y de responsabilidad, ausencia radical de medios para lograr los fines.

En el orden emotivo, por último, la humillación no es menor. Se hace pronto evidente en el texto la imposibilidad del placer. Desconociendo el inescrutable designio divino que determina la posesión de la gracia, desaparece la posibilidad de la verdadera alegría. Sin señal no hay gozo. Y también queda excluida la alegría derivada del goce de los placeres mundanos, al asociar éstos a las tentaciones del mundo y al poder de Satanás. Desde el sistema de ideas inmanente a su dogmática, los seres humanos quedan radicalmente excluidos tanto del goce terrenal como del goce espiritual. No así para Dios, al que le "placen y plugen" muchas cosas. Sin embargo, no es en la ausencia de la alegría y de todas las emociones positivas, como por ejemplo el orgullo, donde se manifiesta con mayor rigor la humillación emotiva. La clave de bóveda de la dogmática calvinista se encuentra en la pura renuncia a toda emoción, en la represión de las emociones que caracteriza, como luego veremos con más detalle, al calvinista. En el texto se habla de "corazón de piedra», y de que plugo a Dios olvidarse de los restantes mortales. El hombre queda así definitivamente aisla- 
do y solo. $\mathrm{Y}$ sin Dios no hay sentimientos. Tampoco hay sentimientos si el hombre no vive entre hombres. "Toda criatura está separada de Dios por un abismo insondable, y ante Él, todos merecemos muerte eterna, salvo decisión suya en contrario, con el solo fin de hacer honra a su propia majestad" (Weber: 97). "Con su patética inhumanidad — nos sigue diciendo Weberesta doctrina había de tener como resultado, en el ánimo de una generación que se entregó a toda su grandiosa consecuencia, el sentimiento de una inaudita soledad interior del individuo. En lo que para los hombres de la época de la Reforma era lo más importante de la vida, la felicidad eterna, el ser humano se veía condenado a recorrer en solitario su camino hacia un destino prescrito desde la eternidad» (Weber: 98). Nada ni nadie podían ayudarle.

Queda así mostrada la cuádruple humillación que proyecta sobre el hombre la doctrina calvinista, humillación que late en la dimensión intercomunicativa del ser humano y que afecta a sus componentes cognitivos, evaluativos, emotivos y rituales. En ninguno de estos órdenes de la cultura aparece el más mínimo asomo de valor capaz de sustentar la dignidad humana. Una conciencia de gusano anida en el hombre que desea redimirse pero que no puede hacer uso de ningún medio. Ni inteligencia, ni moral, ni afectos, ni poder. ¿Cabe humillación más cruel? Así no ha de extrañarnos que el teólogo Milton exclamara con una vehemencia no exenta de resentimiento: "Yo podré ir al infierno; pero un Dios semejante no tendrá nunca mi respeto» ${ }^{4}$.

El ardid de la Razón se revela en el hecho paradójico de que el texto interpretado en los párrafos precedentes hubo de ser escrito por el Hombre. Fue escrito, en efecto, por un hombre.

\section{LOS SENTIMIENTOS DEL CALVINISTA}

El calvinista es olvidado por Dios. Entre ambos se cierne un abismo vacío. La aspiración a lo divino, por este motivo, es sentida intensamente, al mismo tiempo que una gran tristeza inunda al ser que ha sido arrancado de los brazos de la divinidad. Weber nos recuerda la descripción de la conducta de Christian, narrada en el libro más leído de la literatura puritana: "Tras haber advertido que está en la "ciudad de la corrupción", y habiendo oído el llamamiento que le insta a emprender inmediatamente la peregrinación a la ciudad celestial, su esposa e hijos se cuelgan de él, pero se libra de ellos y, tapándose los oídos, va gritando campo a traviesa: Life, eternal life! Ningún refinamiento podría reproducir mejor [...] el estado de ánimo del creyente puritano ocupado sólo de sí mismo, pensando sólo en su propia salvación» (Weber: 102). En pos de un dios imposible, el hombre que nada vale, valora en nada a los otros hombres. «Toda relación sentimental —es decir, no justificada racionalmente - entre hombre y hombre corre el riesgo de incurrir fácilmente en el anatema de idola-

\footnotetext{
${ }^{4}$ Citado en Weber, op. cit., p. 95.
} 
tría por parte de la ética puritana y ascética en general» (Weber: 103). El puritano «cumple con el precepto del amor al prójimo cumpliendo todos los mandamientos divinos para mayor gloria de Dios; con esto ya se da al prójimo lo que se le debe, y todo lo demás corre a cargo de Dios. Desaparece con esto la "humanidad", si cabe decirlo así, de las relaciones con el "prójimo"» (Weber: 104). "No confiar demasiado en la ayuda y en la amistad de los hombres», "Maldito es el hombre que confía en los hombres» (Weber: 100). El vínculo roto con el Ser Supremo se reproduce con cualquier otro ser. Arruinada la intercomunicación con lo sagrado, la dignidad del hombre, de todo hombre, decae a la categoría de mero instrumento. Hoy del dios-Dios, mañana del dios-Dinero.

El calvinista, despojado de todo amor personal, es una persona que apenas puede ocultar su tristeza y depresión. Para Kemper, el sentimiento de depresión procede de un déficit de gratificaciones o recompensas que nos pueden ser ofrecidas voluntaria y personalmente por los otros. En los términos de su teoría sociorrelacional de las emociones, la depresión deriva de una carencia de status (Kemper, 1978). Como hemos visto, el Dios calvinista despoja al hombre de todo orgullo y dignidad, por lo que su estima queda hecha añicos. Pierde el objeto de su deseo, y esta pérdida se manifiesta emocionalmente en su tristeza. No estamos sólo, como señala Weber, ante la «lúgubre doctrina calvinista», sino ante un calvinista lúgubre, triste y deprimido. La pérdida del objeto del deseo también es vista por Freud como la causa de la tristeza. Y si esta pérdida no es todavía segura y absolutamente cierta, como causa de ansiedad. "Junto a la taxativa doctrina de que el mundo de lo creado se halla infinitamente lejano de Dios y de que nada vale por sí, el aislamiento interior del hombre contiene, de una parte, el fundamento de la actitud negativa del puritanismo ante los elementos sensibles y sentimentales de la cultura y religiosidad subjetiva [...]; pero de otra parte, es una de las raíces de individualismo desilusionado y pesimista todavía influyente hoy en el "carácter" nacional y las instituciones de los pueblos de pasado puritano" (Weber: 99) ${ }^{5}$. Pese a la supuesta total subjetividad y "organicidad» de todas las emociones, vemos aquí cómo la depresión, la tristeza, la desesperanza, la desilusión peculiares del carácter calvinista han sido construidas desde un juego complejo de elementos pertenecientes al universo simbólico del hombre.

Sin embargo, estos profundos sentimientos de tristeza y depresión, esta carencia absoluta de amor, la imposibilidad tanto de recibir como de entregar afecto, yacen ocultos bajo el inexpresivo e impertérrito rostro de la efigie calvinista. Emociones a duras penas contenidas y reconocidas que sólo pueden per-

5 El contraste entre la todavía triste y un poco avergonzada humanidad del comerciante Arnolfini, en el cuadro Retrato de Giovanni Arnolfini y su esposa, de Jan van Eyck, pintado en el siglo XV, y la seriedad mortificante y reprimida de los rostros de una pareja de granjeros pintados en el siglo XX por Gran Wood en el cuadro Gótico Americano, que era una actualización del retrato del matrimonio Arnolfini, refleja la huella emocional dejada por la humillación calvinista y por el doble sacrificio impuesto por el capitalismo. 
manecer en su aislamiento interior bajo la coraza férrea de un tesón o sobrehumano o infrahumano. La humillante vergüenza del calvinista, causa de un inmenso dolor, expresa la inseguridad del vínculo social que le une a Dios, a cualquier otro ser humano y, en general, a todos los demás hombres. Para Scheff, la vergüenza indica, precisamente, la existencia de un vínculo débil e inseguro, mientras el orgullo indica, al contrario, un vínculo social seguro. Un vínculo seguro es aquel en el que la distancia social no es ni demasiado grande ni demasiado pequeña. Un vínculo social en el que existe mutuo entendimiento y reconocimiento desde el recíproco respeto y autonomía de los sujetos en interacción (Scheff, 1990). Nada más lejos que los vínculos que la dogmática calvinista establece entre Dios y el hombre. La distancia social que se cierne entre Dios y los condenados al pecado es inmensa e insalvable; se encuentran en perfecto estado de aislamiento (isolation). La distancia social entre Dios y los uncidos por su gracia es nula; se encuentran fundidos en una identificación total (engulfment). En ninguno de los dos casos el hombre goza de autonomía. No merece ningún respeto, ni recibe ningún reconocimiento. Los seres humanos, incapaces de vivir en la más humillante indignidad, pese a estar atrapados por el miedo, encontrarán formas para escapar de este su estado. El ser humano dejará de respetar y de reconocer al viejo Dios, huyendo en busca de un nuevo Dios $y$ de una renovada dignidad.

El hombre moderno, burgués y capitalista, nace por tanto «de» y "con» una profunda y muy dolorosa humillación. Tan mortificante y dolorosa es su angustia y su vergüenza que no le queda otro camino que reprimir sus emociones, hacer de piedra su corazón para resistir su soledad frente a Dios y frente a los otros hombres. La represión de las emociones es clave en el proceso genético del capitalismo, y constituirá de entonces en adelante un rasgo inseparable de la modernidad. Cuanto más penetra la modernidad en el alma de la cultura de un pueblo, en mayor medida se impone la neutralidad y continencia afectiva, mayor será la inexpresividad emocional ${ }^{6}$. Weber ejemplifica este paso haciendo referencia a la diferente sentimentalidad de las doctrinas de Lutero y Calvino. Para Lutero, «el llorar supera al obrar, y el padecer es superior a toda acción» (Weber: 127). Calvino, sin embargo, avanza en el proceso de racionalización instrumental del servicio a Dios hasta límites inconcebibles para Lutero. En el calvinismo toda ascesis del sentimiento, afín a la religiosidad mística, se proscribe radicalmente. Se impone una ascesis moral en la que el individuo figura tan sólo en tanto instrumento de la voluntad divina. "El ascetismo puritano (como todo ascetismo racional) trabajaba para capacitar a los hombres en la afirmación de sus "motivos constantes" [...] frente a los "afectos"; aspiraba, por tanto, a educarlos como "personalidad" "; "la tarea más urgente era terminar de una vez con el goce despreocupado de la espontaneidad vital» (Weber: 120). Todo, pues, confluye en la represión emocional. La insoportabilidad de la vergonzosa humillación, y cualquier válvula emocional de escape

${ }^{6}$ Véanse Scheff (1990a), Elias (1993), Hirschman (1999) y Parsons (1982). 
que pudiera librar al hombre de la misma. Proscrito el goce espontáneo de los placeres; proscrito el goce espontáneo de la interacción con otros hombres. El Hombre retira a Dios del hombre sumiéndolo en una profunda humillación. Rompe todos los vínculos. Anula los afectos. Desintegra el amor.

Las emociones señalan la relevancia para el sujeto de una determinada situación (Hochschild, 1983). Y precisamente por este motivo, en aquella época en la que el mundo personal e íntimo del ser humano nada contaba, las emociones no tenían ningún papel que cumplir. En el origen del capitalismo era necesario domar al hombre. Acallar al hombre para hacerlo capaz de resistir el doble sacrifico. Para acometer este gran cambio, la única emoción que tenía asignado un papel, como así sucede en todos los ritos de paso, siempre traumáticos, era el sentimiento de humillación. Sólo del ansia de amor, de la búsqueda de una nueva dignidad, podía extraerse la fuerza necesaria para surcar esta larga travesía, para llevar a cabo este inmenso cambio social. Previamente, según decimos, como única condición necesaria, había que aislar, hundir y humillar al ser humano.

En su teoría de la personalidad, Alfred Adler señaló que una falta de vínculos sociales seguros, de afecto o de amor, en un momento crucial del desarrollo infantil, ponía al niño en la encrucijada de dos caminos alternativos. El infante, o bien desarrollaba un acusado "complejo de inferioridad", o bien, muy al contrario, despertaba en él una inusitada ansia y "voluntad de poder» (Adler, 1956). En el origen del capitalismo encontramos los dos caminos. Atendiendo a la estructura social, sobre el proletariado recayó el complejo de inferioridad (Sennet y Cobb, 1972) que, posteriormente, Marx tanto hizo por erradicar reclamando para las clases trabajadores el orgullo de ser sujeto de la historia. En la burguesía, por el contrario, anidó la voluntad de poder, de control y de dominio que ha caracterizado a la modernidad desde su mismo nacimiento (Bauman, 1991).

Atendiendo a la doble dimensión de la sociabilidad, esto es, a la dimensión intercomunicativa y a la dimensión interactiva (Bericat, 1999), el complejo de inferioridad en la primera se transmutó, y en esto consistió el principal ardid de la historia, en la voluntad de poder y control de la segunda. Ésta es precisamente la tesis que explica, en nuestra opinión, el enigma emocional del origen del capitalismo. En el orden religioso, corazón de la dimensión intercomunicativa de la sociabilidad, asiento societario de la vergüenza y del orgullo, fundamento de la moral, el hombre se enfrentó a la exquisita crueldad de un deseo imposible. Aquello que más anhelaba, la comunión con Dios, le fue por ese mismo Dios absolutamente negada. Allí, en el orden simbólico de la intercomunicación, la dignidad se convirtió en un objeto imposible, y el hombre en un ser totalmente humillado. Un absurdo lógico y práctico, un juego lúgubre de la historia para quienes hubieron de soportarlo. Ese Dios no tenía sentido para el hombre. Más tarde, un loco acabaría por decir lo que nadie se atrevió a proclamar o lo que nadie supo ver antes que él: que Dios había muerto (Nietzsche, 1987). Así que el hombre, humillado, volvió su mirada en busca de la dignidad, 
allí, en el único lugar que podía encontrarla. Esto es, en el orden de la interactividad, en el juego del poder sobre el mundo, en su afán por dominar el mundo natural, por dominar el mundo social, y por dominar el mundo personal como nunca antes lo había hecho. Hízose instrumento ciego y pétreo de su propia dignidad. Trabajó sin descanso y consiguió el éxito. Pero sólo a costa de una colosal renuncia de sí mismo, de una colosal posposición en el tiempo.

\section{MODERNO, CAPITALISTA Y BURGUÉS}

La gran paradoja de esta tremenda transformación consiste en que el propio universo simbólico que caracterizaba al modelo de sociedad tradicional precedente, catalizó el cambio reordenando y disponiendo a favor de la sociedad moderna fuerzas que emanaban del interior de los individuos particulares. Podría decirse que fue la religiosidad tradicional la que, antes de exhalar su último suspiro, prestó sus servicios de partera en el alumbramiento de un diferente dios. Los rescoldos de la vieja hoguera sirvieron para alumbrar una nueva que, con su luz, generaría pasado el tiempo un distinto cierre en el sentido de la existencia humana, un universo simbólico poblado de tres jóvenes príncipes que, a la postre, lograrían reinar sobre la completa faz de la tierra: el dinero, el trabajo y la racionalidad. Su originaria sacralización religiosa fue dando paso, con el tiempo, a una profunda secularización. Pero eso no mermó ni el poder de su reinado ni la santidad de su sentido. El dios-dinero sacralizó la riqueza convirtiéndola en futuro bienestar material. El dios-trabajo adquirió su forma sacrocarismática en la idea de profesión. El dios-racionalidad santificó a la ciencia presentándola como pura, absoluta y excluyente razón. El hombre se hizo moderno al aplicar el pensamiento racional; burgués al identificarse carismáticamente con su profesión; y capitalista al adorar la riqueza como si fuera un dios. Pero para entender este nuevo olimpo no basta con descubrir la presencia de estos tres dioses, como tres grandes valores que configuran, cada uno por su cuenta, las orientaciones de la conducta y de la existencia humana. Están misteriosamente entrelazados en un complejo único e indisociable. Sólo a efectos de análisis puede desglosarle la triple naturaleza de este nuevo dios, esta triple sacralización de la ascesis intramundana.

Parsons, haciendo referencia a uno de los dioses, dice lo siguiente: «Otro modo en que el espíritu del capitalismo es una antítesis del tradicionalismo es en su relación con los procesos efectivos de actividades adquisitivas. En lugar de aceptar los modos de hacer las cosas en cuanto transmitidos, la actitud capitalista consiste, en cada momento, en reorganizar sistemáticamente sus procedimientos en términos de la tarea total. Sólo el fin último, la maximización del dinero, es "sagrado" "(Parsons, 68: 638). Los fines se imponen sobre los medios, e incluso el hombre en tanto instrumento ha de someterse a la finalidad económica. Estamos, pues, ante un ethos similar al de la religión calvinista, en el que el hombre nada vale, salvo en tanto instrumento de la gloria de 
Dios, aunque ahora este nuevo Dios sea el dinero. La riqueza, el éxito económico intramundano, era fundamental para que el hombre recuperase en la tierra la dignidad que había perdido en el cielo. Desde esta perspectiva, el consumo no podía ser entendido sino como un freno a la acumulación. Por esta causa, todo aquello que ralentizara o impidiera el proceso de acumulación, orientado a recuperar la dignidad de un ser vacío, no podía mostrar ante los ojos de este personaje humillado ningún valor. El capitalista difiere el consumo y difiere el tiempo. Su actividad se rige por una doble diferencia. En primer lugar, la que distingue bienes de consumo orientados a la satisfacción y bienes de capital o capital orientado a la inversión. "Lo que realmente es reprobable para la moral es el descanso en la riqueza, el gozar de la riqueza con la inevitable consecuencia de sensualidad y ociosidad y la consiguiente desviación de las aspiraciones hacia una vida "santa". Sólo por ese peligro del "descanso en la riqueza” es ésta condenable» (Weber: 165). En segundo lugar, una diferencia entre la inmediatez del tiempo presente y el aplazamiento del tiempo expresado en los proyectos de futuro. Por similares motivos a los expuestos, consumir tiempo era sinónimo de perder el tiempo. "Según la voluntad inequívocamente revelada de Dios, lo que sirve para aumentar su gloria no es el ocio ni el goce, sino sólo el obrar; por tanto, el primero y principal de todos los pecados es la dilapidación del tiempo" (Weber: 165). Weber señala que todavía no es tan explícita como en Benjamin Franklin la idea de que "el tiempo es dinero", pero el principio de la importancia del tiempo de vida, el hecho de su escasez, está ya en plena vigencia.

En la transición al capitalismo, no queda otra alternativa al hombre que acumular riqueza y poder. Su problema no es un problema hedonista, sino su carencia de dignidad. "El ascetismo intramundano del protestantismo, podemos decir resumiendo, actuaba con la máxima pujanza contra el goce despreocupado de la riqueza y estrangulaba el consumo, singularmente de artículos de lujo; pero, en cambio, en su efectos psicológicos, destruía todos los frenos que la ética tradicional ponía a la adquisición de las riquezas, rompía las cadenas del afán de lucro desde el momento en que no sólo lo legalizaba sino que lo consideraba querido por Dios» (Weber: 187). "No se pedía la mortificación al rico, sino que usase de sus bienes para cosas necesarias y prácticamente útiles» (Weber: 188). Útiles con respecto al único fin que tenía sentido para un ser humillado.

Esta sacralización del beneficio, junto a la desvalorización de todo medio salvo en la medida que contribuyera al logro de la riqueza, puso en primer plano la lógica de las consecuencias. De su mano avanza con ímpetu una moral utilitarista que no se pregunta por el ser de las cosas, sino por su función, por las consecuencias que comporta su existencia para un fin determinado. De ahí la prevalencia de la racionalidad instrumental y del cálculo (Bendix, 1979). De ahí, también, la importancia de la creación de un mercado de mano de obra formalmente libre, y de la existencia de individuos liberados de todos sus vínculos sociales. Los in-puts se valoran exclusivamente por su contribución a 
los out-puts, condición necesaria para el cálculo de capital, tan querido al capitalismo en la medida que persigue la organización de sistemas socioeconómicos que garanticen de forma constante y regular la maximización de los beneficios. Tomar en cuenta las consecuencias constituye la base de los principios de productividad, eficiencia y rentabilidad que constituyen el núcleo de la organización capitalista. Organización que, por supuesto, también afecta al trabajo y determina los diversos modos de alienación típicos de este sistema. El ethos del capitalismo se expresa en la planificación de la empresa racional burguesa y en la organización racional del trabajo. El dios-dinero junto al trabajo y a la razón.

En opinión de Weber, "es evidente que en la palabra alemana "profesión" (Beruf), como quizá más claramente aún en la inglesa calling, hay cuando menos una reminiscencia religiosa: la idea de una tarea impuesta por Dios» (Weber: 67). Este tinte religioso estaba ausente tanto en la cultura católica como en la antigüedad clásica, y fue introducido por la Reforma alterando el sentido original de los textos bíblicos. «En todo caso, lo absolutamente nuevo era considerar que el más noble contenido de la propia conducta moral consistía justamente en sentir como un deber el cumplimiento de la tarea profesional del mundo. Ésta fue la consecuencia inevitable de la idea de una dimensión religiosa del trabajo cotidiano, que, a su vez, engendró el concepto de "profesión" en este sentido" (Weber: 74). Lo que fue en Lutero una primera aproximación entre moral y obrar cotidiano, se convirtió en el calvinismo en una obsesión imbuida de intensa religiosidad. Se rechaza la odiosa contemplación, y se santifica el obrar como único modo de agradar a Dios. En la obra del predicador Baxter abundan las referencias a favor del trabajo duro y continuado. «El trabajo es fundamentalmente el fin propio de la vida, prescrito por Dios» (Weber: 169). No es, como fuera en Tomás de Aquino, una obligación natural que alcanza hasta donde llegan las necesidades, sino un destino, un mandato, el desempeño de una función que nos ha sido encomendada en el mundo. «En efecto: aquella idea peculiar - $\tan$ corriente hoy y tan incomprensible en sí mima- del deber profesional, de una obligación que debe sentir el individuo, y siente de hecho, ante el contenido de su actividad "profesional" [...], es la más característica "ética social" de la civilización capitalista" (Weber: 43).

En esta concepción del trabajo se percibe con claridad la ausencia de esquemas utilitaristas, pues nada hubiera podido justificar el hecho de que también el rico, no sólo el necesitado, hubiera de trabajar con denuedo en el marco de su profesión. Sin esta fundamentación religiosa no se habría logrado santificar el sacrificio del trabajo que está en el origen del capitalismo. Un trabajo perpetuo y constante que tiene valor en sí mismo como marca de la identidad moral y de la identidad social del individuo. Un trabajo que, si bien es asociado originalmente por Weber a su teoría de la comprobación, como cuando escribe que «se inculcó el trabajo profesional incesante como único modo de ahuyentar la duda religiosa y de obtener la seguridad del propio estado de gracia», es estimulado ante todo para ahuyentar la humillación. Weber mismo 
reconoció la importancia de este efecto al incluir una nota a pie de página al final de su referencia a "el trabajo profesional incesante». Refiriéndose a las admoniciones contenidas en el Christian Directory de Baxter, dice lo siguiente: «Esta recomendación del trabajo profesional como medio de ahuyentar la angustia suscitada por el sentimiento de la propia inferioridad moral recuerda la interpretación psicológica que daba Pascal al afán de dinero y la ascesis de la profesión, como un medio para engañarse sobre la propia nulidad ética. En él, el dogma de la predestinación va unido a la convicción de la insignificancia que el pecado original ha impreso en toda criatura» (Weber: 109). Sin lugar a dudas, la angustia de la que aquí se habla no es ya la que corresponde a la incertidumbre, en el marco de una necesidad de comprobación, sino la de la inferioridad moral, esto es, la de la dolorosa vergüenza, la de la insignificancia a la que alude, muy precisamente, Pascal.

De ahí que el sacrificio de la ilimitada disposición al trabajo no tenga como objeto fundamental eludir las tentaciones del mundo, sino la recuperación de la dignidad en el orden intramundano, dignidad que ahora no sólo se orienta al éxito económico, sino a un modo de ser que es, en última instancia, un modo de hacer (Sennet, 1998). Sin duda, el trabajo incesante y metódico está asociado al éxito capitalista. «Entonces aparecen unidas en estrecho maridaje la capacidad de concentración del pensamiento y la actitud rigurosamente fundamental de "sentirse obligado" al trabajo, con el más estricto sentido económico, que calcula la ganancia y su cuantía, y un austero dominio de sí mismo y una moderación que acrecienta extraordinariamente la capacidad del rendimiento en el trabajo. Éste es el suelo más abonado para la consideración del trabajo como fin en sí, como "profesión”, que es lo que el capitalismo exige» (Weber: 53). Pero este sentido religioso de la profesión mundana también está asociado, por otra parte, a la racionalidad. No se trata de un obrar arbitrario, sino de una actividad metódica, ordenada según reglas externas, o modus operandi, que exigen del individuo un activo control. En este sentido, el profesional y el burócrata comparten una lógica de actividad común basada en el autocontrol, en la autodisciplina y en el dominio de sí mismo. "El dios calvinista no exigía de sus fieles la realización de tales o cuales "buenas obras", sino una santidad en el obrar elevada a sistema. Nada de la oscilación católica (auténticamente humana) entre el pecado, el arrepentimiento, la penitencia, el descargo y la vuelta a pecar [...]. La conducta moral del hombre medio perdía así su carácter anárquico y asistemático, para configurarse como un método consecuente de un estilo de vida total. No es, pues, un azar que se hayan quedado con el nombre de "metodistas" los adeptos del último gran renacimiento de la ideas puritanas en el siglo XVIII, así como en el siglo XVII se había aplicado a sus antecesores espirituales la calificación equivalente de "precisistas" " (Weber: 117). Un ascetismo moral orientado al obrar sistemático en el marco del logro para el individuo de una digna identidad social.

La última sacralización en el proceso de alumbramiento de este trino politeísmo intramundano es la que santifica la racionalidad. Última pero no 
menos importante, puesto que la modernidad del capitalismo y de la profesión sólo pueden entenderse en su integridad como búsqueda racional del lucro y como ordenación racional del trabajo. En su sentido absoluto, la modernidad se despliega como racionalidad del hacer vinculada a la racionalidad del saber en busca no del conocimiento de sí, ni siquiera de su perfeccionamiento moral, sino en busca del dominio sobre el mundo. El lucro en tanto fin último, dios-dinero, y la profesión en tanto fin último, dios-profesión, se despliegan en un esquema de medios-fines cuya adaptación sólo puede ser revelada desde la racionalidad instrumental (Horkheimer, 1973). Tanto en la conciencia humana como en la cultura social, los valores y las emociones son recluidos en el universo de lo irracional. Podemos adorar a Dios o al Becerro de Oro, pero en nuestros valores últimos nada puede decir la racionalidad. Podemos sentir esto o lo otro, pero toda emoción es en sí misma irracional. El conocimiento objetivo del mundo, el componente cognitivo de la conciencia, se impone como nuevo dios de la modernidad. Conocimiento que deja aparte, incuestionadas, tanto la intersubjetividad implícita en los valores sociales como la subjetividad implícita en los estados emocionales del individuo. La conciencia se vuelca hacia el exterior, disipando al sujeto en el marco operativo de los vínculos entre acciones y consecuencias revelados por procesos simbólicos meramente cognitivos. De ahí el desencantamiento en un mundo que proscribe la magia, el rito y todo acto sacramental tan sólo porque estas actividades están orientadas directamente al mundo personal y social del sujeto. Actividades que sólo estarían justificadas en el marco de una cultura que considerara al hombre como un valor final, como un fin en sí mismo. Mas si el individuo nada vale, como así aparece en la dogmática calvinista, y es tan sólo un mero instrumento, un medio para el logro de otros fines, la única razón legítima será aquella que descubra consecuencias sobre el mundo, conexiones entre conducta y efectos, esto es, racionalidad instrumental. Otro nuevo diferir, el de la razón, que no piensa directamente al sujeto, sino, indirectamente, en las modificaciones del mundo que pueden interesar y alterar a ese mismo sujeto. La ilustración, sin duda, es la cara alegre y optimista de este nuevo modo de pensar. La ciencia, sobre todo la ciencia positiva, su logro más señero.

\section{CONCLUSIÓN}

Según hemos visto, la ética protestante no es sino el paradójico catalizador de una tremenda transvaloración de todos los valores, de un cambio social sin precedentes en la historia de la humanidad. De un complejo de valor de carácter extramundano ha de pasarse a un sistema de valores intramundano. Y la argucia de la razón se muestra, precisamente, en su capacidad para utilizar los viejos dioses para crear los nuevos. Toda transformación social, en la medida que afecta a la identidad, puede entenderse como un rito de paso. En estos 
ritos, cuyo único objeto es una transformación lo más rápida y completa del individuo, hay dos claves fundamentales que garantizan su éxito. Una de ellas estriba en causar al individuo un radical aislamiento, una ruptura lo más perfecta posible de sus vínculos sociales precedentes. La otra se propone una anulación completa, un despojamiento absoluto, de sus marcas de identidad. Estas dos estrategias, como ya hemos visto, no tienen otro sentido que provocar en el sujeto una profunda humillación. Si la vergüenza señala el estado de nuestros vínculos sociales, en este caso inseguros, el aislamiento y la soledad no pueden producir sino vergüenza. Por otro lado, si la vergüenza constituye una ausencia de valor de nuestra persona ante los ojos de los demás, la destrucción de todas la marcas de identidad no es otra cosa que una flagrante humillación de lo que antes habíamos sido. Con estas dos operaciones el hombre queda vacío, solo y sin valor, se le constituye como vacío solitario que aspira profundamente al amor, al vínculo y a la identidad social (Lindholm, 1997); en suma, a una renovada dignidad en tanto que hombre. De este vacío extraen los ritos de paso y los procesos de resocialización la energía que finalmente dará luz al milagro del cambio (Goffman, 1961). Así es como debe entenderse, en nuestra opinión, la tesis weberiana de la ética protestante y el espíritu del capitalismo. Así es como se pone de manifiesto en el propio texto, a condición de que atendamos a la importancia del papel que cumple el componente emocional en su modelo teórico. Podría concluirse que no existe tesis sociológica veraz, ni plausible ni inteligible, si se prescinde del componente emocional de una cultura y de una conciencia, a la que también pertenecen por derecho propio, con idéntico derecho, los componentes cognitivos y valorativos, es decir, las ideas y los valores.

La humillación en el orden intercomunicativo, orden cuya expresión más esencial es sin duda el ámbito de lo sagrado, condujo al hombre a ese paradójico destino que consistió en renunciar a Dios al mismo tiempo que lo adoraba, más exactamente, por el mismo hecho de adorarle. Pequeños cambios dogmáticos, por efecto de sus consecuencias emocionales, logran modificaciones radicales de la conducta humana. Separado de Dios, olvidado por la divinidad, muerto de vergüenza, el hombre se lanza a la búsqueda del orgullo en el único mundo en el que podía encontrarlo, esto es, en el orden de la interactividad y de la potencia, en el orden del poder y del tener. De ahí su conducta agresiva, rígidamente metódica, sistemática y fundamentalmente obsesiva. De ahí su rigidez moral y su odio a los demás. De la ascesis del sentimiento de Lutero, a la ascesis moral de Calvino. Una ascesis que sirve para demostrar al hombre su potencia, una ascesis que potencia la voluntad de poder y el ansia de dominio del hombre. Es el paso que en la filosofía se da, de acuerdo con Simmel, entre las ideas de Schopenhauer y las de Nietzsche (Simmel, 1915). Lutero y Schopenhauer valoran el sentimiento como modo de comunicación con lo divino y como fuente de toda moral. Reclaman una aristocracia del ser. Por su parte, Calvino y Nietzsche se orientan al dominio del mundo. En Calvino esta voluntad estaba todavía afectada por el resentimiento, por la triste búsqueda 
de la comunión con Dios. Pero, para Nietzsche, Dios ha muerto, y la voluntad de poder constituye la raíz y la matriz de un renovado orgullo que se expresa a sí mismo no sólo con la declaración explícita de la muerte de Dios, sino con la configuración del hombre en su propio Dios. La figura del superhombre nietzscheano rebosa energía en la medida que manifiesta sin cortapisas su voluntad de poder y su absoluto valor. Pero es también producto del resentimiento, un reflejo especular, una inversión absoluta de todos los valores que también incorpora un no reconocimiento de la vergüenza. Aquí también se despliega la lógica íntima de la modernidad, un solo Dios, el individualismo, y un solo objeto, la voluntad de poder. Absoluto dominio interactivo del mundo, sea éste natural (energía), social (poder) o personal (voluntad). El individuo dominará pero sólo a costa de ser dominado. Nueva paradoja que abrirá, más adelante, las puertas de la posmodernidad.

\section{BIBLIOGRAFÍA}

Adler, A. (1956): The Individual Psychologie of Alfred Adler, New York, Basic.

Aron, R. (1980): Las etapas del pensamiento sociológico, II, Buenos Aires, Siglo Veinte.

Bauman, Z. (1991): Modernity and ambivalence, Cambridge, Polity Press.

Beltrán, M. (1978): «Acerca de Weber y su ciencia exenta de valoraciones», en J. Jiménez Blanco y C. Moya Valgañón (comps.), Teoría sociológica contemporánea, Madrid, Tecnos.

BendiX, R. (1979): Max Weber, Buenos Aires, Amorrortu.

Bericat Alastuey, E. (1998): La integración de los métodos cuantitativo y cualitativo en la investigación social. Significado y medida, Barcelona, Ariel.

- (1999): «El contenido emocional de la comunicación en la sociedad del riesgo. Microanálisis del discurso", en REIS, núm. 87, pp. 221-253.

- (2000): «La sociología de la emoción y la emoción en la sociología», en Papers, núm. 62, pp. 145-176.

- (2001): «El suicidio de Durkheim o la modernidad de la triste figura», en Revista Internacional de Sociología, RIS, núm. 28, pp. 69-104.

BERLIN, I. (1999): Las raíces del romanticismo, Madrid, Taurus.

Cooley, Ch. H. (1902): Human Nature and Social Order, Nueva York, Scribner's.

EisenSTADT, E. N. (dir.) (1968): The Protestant Ethic and Modernisation, Basic Books.

ELIAS, N. (1993): El proceso de la civilización. Investigaciones sociogenéticas y psicogenéticas, México, Fondo de Cultura Económica.

Freund, J. (1973): Sociología de Max Weber, Barcelona, Península.

Gerth, H. H., y Mills, C. W. (1972): «Introducción. El hombre y su obra», en Max Weber, Ensayos de sociología contemporánea, Barcelona, Martínez Roca.

Giddens, A. (1976): Politica y sociología en Max Weber, Madrid, Alianza.

- (1977): El capitalismo y la moderna teoría social, Barcelona, Labor.

Giner, S. (1978): «Intenciones humanas y estructuras sociales: aproximación crítica a la lógica situacional», en J. Jiménez Blanco y C. Moya Valgañón (comps.), Teoría sociológica contemporánea, Madrid, Tecnos.

Gobernado Arribas, R. (1980): "Weber y la ética protestante: estado actual de la cuestión», mecanografiado, Departamento de Sociología, Universidad de Málaga.

GoffMAN, E. (1956): «Embarrasment and Social Organization», en The American Journal of Sociology, núm. 62, pp. 264-271.

- (1961): Asylums: Essays on the Social Situation of Mental Patiens and others Inmates, Nueva York, Anchor Books. 
GONZÁlEZ LEÓN, R. (1998): El debate sobre el capitalismo en la sociología alemana, Madrid, CIS.

Gordon, S. L. (1981): "The Sociology of Sentiments and Emotions», en M. Rosenberg y Ralph H. Turner, Social Psychology. Sociological Perspectives, Nueva York, Basic Books, Inc., Publishers.

Habermas, J. (1999): Teoría de la acción comunicativa, I y II, Madrid, Taurus.

Hirschman, A. O. (1999): Las pasiones y los intereses, Barcelona, Península.

Hochschild, A. R. (1979): «Emotion Work, Feeling Rules, and Social Structure», en American Journal of Sociology, núm. 85, pp. 551-575.

- (1983): The Managed Heart. Commercialization of Human Feeling, Berkeley, University of California Press.

Horkheimer, M. (1973): Crítica de la razón instrumental, Buenos Aires, Sur.

Hume, D. (1981): Tratado de la naturaleza humana, Madrid, Editora Nacional.

JimÉNEZ BlanCO, J. (1978): «Weber, Schütz y Garfinkel sobre racionalidad», en J. Jiménez Blanco y C. Moya Valgañón (comps.), Teoría sociológica contemporánea, Madrid, Tecnos.

Kemper, Th. D. (1978): A Social Interactional Theory of Emotions, New York, John Willey \& Sons.

- (1981): «Social Constructionist and Positivist Approaches to the Sociology of Emotions», en American Journal of Sociology, vol. 87, núm. 2, pp. 336-362.

Kofler, L. (1974): Contribución a la historia de la sociedad burguesa, Buenos Aires, Amorrortu.

LANDES, D. S. (comp.) (1971): Estudios sobre el desarrollo del capitalismo, Madrid, Ayuso.

LEWIS, H. B. (1971): Shame and Guilt in Neurosis, Nueva York, International University Press.

Lindholm, Ch. (1997): Carisma. Análisis del fenómeno carismático y su relación con la conducta humana y los cambios sociales, Barcelona, Gedisa.

MarX, K. (1964): El Capital. Crítica de la economía política, México, FCE.

- (1972): Elementos fundamentales para la crítica de la economía politica, Madrid, Siglo XXI.

Mitzman, A. (1976): La jaula de hierro. Una interpretación histórica de Max Weber, Madrid, Alianza.

Mommsem, W. (1981): Max Weber: Sociedad, politica e historia, Buenos Aires, Alfa.

Mommsem, W. J., y Osterhammel, J. (eds.) (1987): Max Weber and his Contemporaries, London, Unwin Hyman.

MoyA, C. (1978): "Argumentos para otra ciencia social», en J. Jiménez Blanco y C. Moya Valgañón (comps.), Teoría sociológica contemporánea, Madrid, Tecnos.

Nietzsche, F. (1987): La Gaya ciencia, Madrid, Akal.

PARSONS, T. (1968): La estructura de la acción social II, Madrid, Guadarrama.

- (1982): El sistema social, Madrid, Alianza.

RUANO DE LA FuENTE, Y. (1996): Racionalidad y conciencia trágica. La modernidad según Max Weber, Madrid, Trotta.

SAHAY, A. (comp.) (1974): Max Weber y la sociología alemana, Buenos Aires, Paidós.

SCAFF, L. A. (1989): Fleeing the Iron Cage. Cultura, Politics and Modernitiy in the thought of Max Weber, Berkeley, University of California Press.

Scheff, Th. J. (1988): "Shame and Conformity: The Deference-Emotion System», en American Sociological Review, vol. 53, pp. 395-406.

- (1990a): Microsociology. Discourse, Emotion and Social Structure, Chicago, The University of Chicago Press.

- (1990b): «Socialization of Emotions. Pride and Shame as Causal Agents», en Theodore D. Kemper (ed.), Research Agendas in the Sociology of Emotions, Albany, State University of New York.

- (1994): Bloody Revenge. Emotions, Nationalism, and War, San Francisco, Westview Press.

SENNETT, R. (1998): La corrosión del carácter, Barcelona, Anagrama.

Sennett, R., у Совв, J. (1972): The Hidden Injuries of Class, Nueva York, W. W. Norton \& Company.

Sнотт, S. (1979): «Emotion and Social Life: A Symbolic Interactionist Analysis», en American Journal of Sociology, vol. 84, núm. 6, pp. 1317-1334. 
Simmel, G. (1915): Schopenhauer y Nietzsche, Madrid, Francisco Beltrán.

- (1977): Filosofía del dinero, Madrid, IEP.

SMITH, A. (1997): La teoría de los sentimientos morales, Madrid, Alianza.

TAWNeY, R. H. (1959): La religión en el origen del capitalismo, Buenos Aires, Dédalo.

VV.AA. (1971): Presencia de Max Weber, Buenos Aires, Nueva Visión.

Weber, M. (1979): Economía y Sociedad, México, Fondo de Cultura Económica.

- (1998): Ensayos sobre sociología de la religión, I, Madrid, Taurus.

Willard Gaylin, M. D. (1984): The Rage Within. Anger in Modern Life, Nueva York, Penguin Book.

\begin{abstract}
A very detail analysis of sociological theories developed by classical sociologists proof that it is necessary to consider the emotions of social phenomena to fully understand that theories. This principle sound to modern sociologists like a very strange idea, given that modern social science tried hardest to exclude emotions from its theoretical models. Based on the sociology of emotions, this article analyses Weber' The Protestant Ethic and the Spirit of Capitalism from a emotional point of view.

According to Weber' thesis, the predestination dogma, that is, the belief that everything that happens has been decided in advance by God, is at the origin of the spirit of capitalism. However, it is not merely the belief, but the emotion that this belief evoke in the believers, a profound anguish about their destiny, what oriented protestants towards worldly success. So, an idea, even links to a value, cannot motivate human behavior without a correspondent emotion. A specific system of the three basic components of a culture, that is, cognitive, evaluative, and emotive are necessary.

However, from our point of view, anguish, a rather generic sentiment, is unable to make intelligible the causal connection between the protestant ethic and the spirit of capitalism. Interpreting Weber's text, we propose that humiliation is the specific and strong sentiment elicited by protestant doctrine. This religion threw a triple humiliation over human beings. First, human beings know nothing about their destiny, but God is omniscient (cognitive humiliation). Second, human beings deserve no respect before God (evaluative humiliation). And third, human beings have not a right to felicity (emotive humiliation). This unbearable and absolute absence of dignity created a strong motivation to pursuit a renewed pride. Then, a radical change of values took place: from eternal salvation to worldly success, from traditional society to modern society.
\end{abstract}

